\title{
Losing our way with mapping: Thinking critically about marine spatial planning in Scotland
}

\author{
Glen Smith ${ }^{a}$, Ruth E. Brennan ${ }^{b}$ \\ a School of Geosciences, Geography Building, Drummond Street, Edinburgh EH8 9XP, \\ Scotland, UK \\ ${ }^{b}$ Centre for Sustainable Coasts, Scottish Association for Marine Science, Scottish Marine \\ Institute, OBAN, Argyll PA37 1QA, Scotland, UK
}

This is the accepted manuscript of a paper originally published in Ocean \& Coastal Management. You may find the final, formatted version at 10.1016/j.ocecoaman.2012.08.016.

\section{Abstract}

Marine spatial planning (MSP) is the dominant management tool for marine environments around the world and is an attempt to move beyond the sectoral governance of marine spaces. Scotland is no exception and MSP is central to its management plans. The interpretation and use of spatial data informs these plans and maps provide the backbone of the decision-making process. Whilst not refuting MSP as a governance tool, this paper examines more closely some of the inherent problems with representing marine environments spatially and how the practice of map-making inevitably interacts with social-ecological networks. Borrowing from critical cartography and Actor-Network Theory (ANT), four observations are made: 1) due to the necessary procedure of categorising and simplifying data, maps do not always accurately represent changeable marine environments and situations; 2 ) maps can produce reality as much as represent it; 3 ) mapping has become the point through which all actors and stakeholders must pass; 4) as they are obliged to pass through this point, the roles and definition of certain actors can change. This discussion of marine spatial planning in Scotland demonstrates what can be learnt from viewing marine spaces as a tightly coupled socialecological environment.

\section{Introduction}

Increasing user conflict over Scotland's marine spaces has led to an overhaul of their management within a rapidly changing policy environment. In 2002, the UK Government, together with the devolved administrations of Scotland, Wales and Northern Ireland, set out their shared vision for the marine environment of 'clean, healthy, safe, productive and biologically diverse oceans and seas' (Defra, 2002). Scotland is also committed to a number of high level marine objectives (HLMOs), which were agreed by England, Scotland, Northern Ireland and Wales (HM Government, 2009). These HLMOs underpin the 2011 Marine Policy Statement, agreed by the four administrations, which sets out shared policies to contribute to achievement of sustainable development in the UK marine area (HM Government, 2011). 
The Marine (Scotland) Act 2010 has paved the way for the National Marine Plan (currently being drafted), which aims to shape national objectives and policies surrounding Scotland's coastal and marine management. The strategic objectives of the National Marine Plan include making Scottish businesses and people wealthier and the distribution of this wealth fairer, whilst ensuring that natural and built environments are greener (Scottish Government, 2011a). Purpose targets include continued sustainable economic growth whilst ensuring sustainability by reducing greenhouse gas emissions. The National Marine Plan will inform the Regional Marine Plans which will be put in place for each Scottish Marine Region, the boundaries for which have been consulted on but not yet finalised (Scottish Government, 2011b).

Marine Spatial Planning (MSP) features heavily in approaches to marine management worldwide, and allows sectoral pressures on marine spaces and resources to be managed more effectively (Douvere, 2008; Gilliland and Laffoley, 2008; Halpern et al., 2008). At European level, the Integrated Maritime Policy has initiated a series of important projects, including a call for individual member state roadmaps towards marine spatial planning (European Commission, 2007). In keeping with the European adoption of the MSP approach the Advisory Group on Marine and Coastal Strategy (AGMACS) concluded in its recommendations for Scotland that "[t] here should be a system of Marine Spatial Planning... [with]...a statutory basis" (Scottish Government, 2007). As MSP relies on spatial analyses of marine environments, mapping practices were one of the key activities for which funding from Europe was allocated (European Commission, 2008). In Scotland the Marine Atlas (Baxter et al., 2011) is evidence of the extensive spatial data collection and analysis that has been invested in to date.

This paper focuses on the spatial aspects and mapping processes of MSP in a Scottish context. Borrowing elements from critical cartography and Actor-Network Theory, a theoretical framework is used to expose delicate networks that are concealed by mapping processes and by maps themselves. This paper questions the ontological security or inherent reliability of the maps being created within the marine planning process in Scotland by raising four key points in the discussion of mapping practices and, in turn, marine spatial planning. These are as follows:

- due to the necessary procedure of categorising and simplifying data, maps do not always accurately represent changeable marine environments and situations;

- maps can produce reality as much as represent it;

- mapping has become the point through which all actors and stakeholders must pass;

- as they are obliged to pass through this point, the roles and definition of certain actors can change.

The aim of this paper is to highlight some of these potential pitfalls associated with mapping as a central element to MSP. Critical analysis is key to ensuring that MSP achieves outcomes that better represent how different stakeholders interact with marine environments. These four points do not emerge strictly in order. Instead, Sections 3e4.3 show how these issues are highlighted by critical cartography and Actor-Network Theory, before being considered in the context of Scotland in Sections 5-8. 


\section{Methodology}

Between March and August 2011 the corresponding author investigated the ontological security of the maps being created within the Scottish marine planning process through an extensive literature review combined with semi-structured interviews in formal and informal settings. Interview subjects included experts from Scottish Natural Heritage (SNH) and the Joint Nature Conservation Committee (JNCC), creel and scallop fishermen on Scotland's west coast, members of staff at the Scottish geographic information system (GIS) department (Geographic Information Science \& Analysis Team - GI-SAT) and leading experts at the international conference People and the Sea VI: Bridging Science and Policy for Sustainable Coasts and Seas, Amsterdam, July 2011. Attendance at several policy workshops and stakeholder meetings also contributed to understanding the viewpoints of various stakeholder groups. This paper is an adapted version of findings presented in a Masters degree dissertation (Smith, 2011).

\section{Challenging maps}

Critical cartographers have attempted to show how mapping practices produce reality, as much as represent it, and that mapping can be "performative, participatory and political" (Crampton, 2009 , p. 840). Kitchin and Dodge (2007) focus on mapping interactions both prior to and after map creation because without this a map is nothing more than "coloured ink on a page" ( $p$. 335). Arguing that maps lack ontological security suggests that they can only "open, and cannot close, debate on the state of the world" (Robbins in Zimmerer and Bassett, 2003, p. 198). From a critical cartography perspective the creation and use of a map might be depicted as in Fig. 1.

In Fig. 1 processual inputs are given on the left. These contribute to the creation of the map, which quickly becomes redefined by the way it is used, interacted with and interpreted, as shown on the right. The original inputs (and associated networks) are hidden as the map performs an action. The range of actions is vast and the map is redefined through every one. The diagram also demonstrates the map's inability to represent changing situations over time. Its conception is a mere snapshot of the processes that contributed to its making and of the situation it is designed to represent. Furthermore, the processes leading to the map do not cease at the point of its creation but continue. As Knol puts it, "[t]his constitutes a paradox in mapping practices as a means to acquire control over an area or situation, as enduring mapping exercises continuously challenge...boundaries" (Knol, 2011b, p. 991).

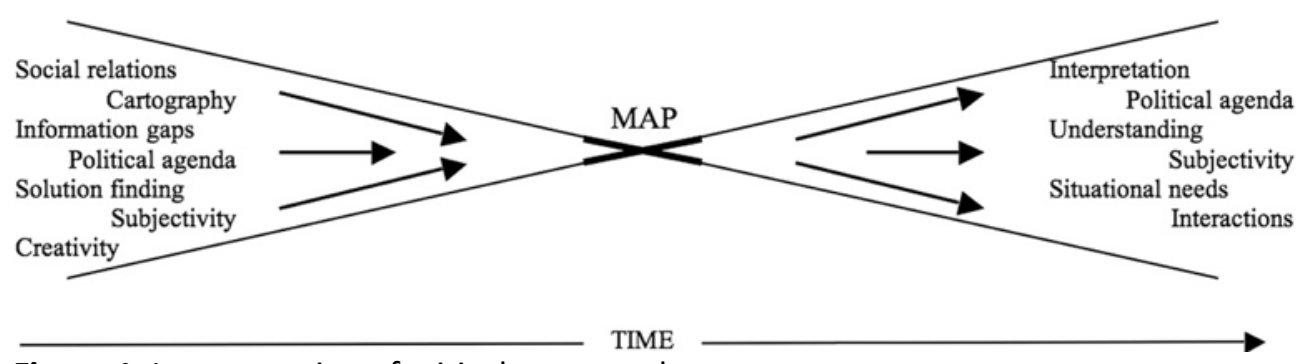

Figure 1. Interpretation of critical cartography arguments.

Geographical information systems have become an essential tool for informing the management of marine areas, especially through Marine Spatial Planning. Although GIS allows 
us to analyse a diverse range of geographically-related phenomena, experts have pointed to its limitations. Many of these limitations relate to problems of scale. For example, Reed et al. (2012) express doubts over the computational efficiency of GIS software over large scales and Vine et al. (1997) point to the limits to the interpretation of multiple overlaid map layers, again stating that large scales cause problems for the relevance of GIS maps. These criticisms relate directly to some of the points made in this paper about discrepancies between visual representations of reality and what might actually be occurring on a local level. In addition to this, the parameters set in the collection and collation of data used to create GIS maps are decided upon by those managing the software and mapping processes. Therefore, GIS is no less susceptible to the creativity and selectivity portrayed in Fig. 1.

\section{Revealing networks}

It is useful to further investigate the networks that perhaps escape recognition by the map and are consequently absent from the diagram above. Networks define the world around us. ActorNetwork Theory (ANT) regards "stable sets of relations or associations as the means by which the world is both built and stratified" (Murdoch, 1998, p. 359). ANT has as its primary objective the exposure of these relations and the networks that they form. The accounts of ActorNetwork Theory are abundant and detailed (see Law, 1992; Latour, 1993; Murdoch, 1997, 1998; Steins, 2001) and it has been used on numerous occasions to analyse natural resource issues (Eden et al., 2000; Kaljonen, 2006; Knol, 2011b; Roger et al., 2009). The critiques of ANT are also plentiful (see Castree and MacMillan, 2001; McLean and Hassard, 2004; Nightingale, 2006) and some of them very convincing. It is the view of the corresponding author that ANT has its limitations (discussion of which is beyond the scope of this paper) but the theory nevertheless retains its value for probing complex issues. What follows is a brief summary of the relevant aspects of Actor-Network Theory.

\subsection{Blurring the boundaries}

A particular strength of ANT is its willingness to look beyond binary opposites. Oppositional categories are mutually exclusive and present an either/or interpretation of our world, such as the society/nature or the society/technology distinction. By seeking the delicate networks that include human and non-human 'actants', ANT attempts to demonstrate that oppositional categories such as society and nature are conceptually inseparable. This has led scholars to extend the social into nature (such as 'social nature' in Castree and MacMillan, 2001) and into other realms such as technology (Latour, 1993). This is a useful approach for challenging the view of maps as providing the final word on an issue. Residents, tourists, stakeholders, land users, marine space users (in short, all those who interact with maps) will commonly either accept the binary classification of inside/outside of a particular zone or find it hard to resist judgement based on the 'evidence' that maps provide. As important details are often omitted from maps (either consciously to achieve 'best-fit' results or unconsciously due to ignorance of situated stories) we are justified in questioning the definitiveness of the lines on them. 


\subsection{The issue of agency}

Importantly, and somewhat controversially (see for example, Pels 1995 in McLean and Hassard, 2004), ANT grants agency to non-humans by demonstrating their importance in the actions and characteristics of the social. It appears that ethically the theory is treading on thin ice here but a reading of ANT literature helps to clarify some important points. Firstly, it is not the aim of ANT to grant intentionality to non-human agents. A desk, for example, is not going to intentionally enable you to sit and write a letter any more than it is going to intentionally conspire against your doing so. The agency of the desk lies in its relationship to other actants, of which the letter-writer is just one. Claiming that the desk is the most important actant is misguided, but suggesting that a letter is just as easily written without it is equally so. This demonstrates the second point, that agency does not assume intentionality. Thirdly, ANT does not aim to prioritise agents/non-agents, humans/non-humans, subjects/objects. There is no reason to assume that either people or objects are more important to the network make-up, change or failure. However, Law must be heeded on this point before the attacks rain down from a humanistic perspective: "[t]o say that there is no fundamental difference between people and objects is an analytical stance, not an ethical position" (Law, 1992, p. 383). Thinking more openly about agency might highlight new relationships and actants present in marine use and governance.

\subsection{Obligatory passing points (OPPs)}

The way that familiar networks can be easily assimilated into our everyday routines is referred to by Law (1992) as 'punctualisation'. These networks appear in the form of "agents, devices, texts, relatively standardised sets of organisational relations, social technologies, boundary protocols, organisational forms" (Law, 1992, p. 385). We utilise these networks when going to the post office, paying bills, writing letters etc. It can be argued that a map is such an agent, and in so doing it is crucial that we reflect on how maps underpinning the National Marine Plan arrive at a point where they can dictate our relationship to the sea as a natural resource. How this might occur was described in detail by Callon (1998) in his study of the scallops of St Brieuc Bay in North-Western France. Through a process called 'problematization' the various research questions posed by scientists studying the scallops' characteristics become an obligatory passing point (OPP) for all actants and stakeholders. In short, it is through "multilateral negotiations, trials of strength and tricks" that the overall network is shaped and certain relationships are either blocked or strengthened (Callon, 1998, p. 74). Section 7 below explores this idea further in the context of how problematization and OPPs are being established under Scotland's National Marine Plan.

\section{The networks of networks}

In order to produce maps vast amounts of data need to be collected, analysed and categorised. This process inevitably involves simplification and best-fit practices, as the full spectrum of an area's characteristics cannot be represented on a map. As a means of demonstrating how complex realities are simplified through categorisation, Johnsen et al. (2009) provide a 
comprehensive study into how the Total Allowable Catch, or the 'TAC machine', led to the 'cyborgization' of the fisheries in Norway. According to the authors this was done so that 'a division of labour between scientists and managers could be established' (Johnsen et al., 2009, p. 15). The TAC system is the main unit of catch measurement informing global fishing regulations such as in the European Common Fisheries Policy. This process was intended to transform the organic and unmanageable entity that is fish into a 'domesticated manageable object' (Johnsen et al., 2009, p. 17). This simplification can, it is argued, produce measurements that distort reality, with the resulting data often telling a misleading story of actual catches and fishing experiences. These claims that simplification produces measurements that distort reality can be supported by examples of similar processes in the making of the Marine Atlas (Baxter et al., 2011). One such example is the mapping of fishing effort in kw Days (Baxter et al., 2011, p. 148e9), which is a calculation based on engine size and days spent at sea fishing (engine size multiplied by calendar days).

In an attempt to explore the possibility of data misrepresenting the reality of fishing activities the corresponding author spent time at sea with creel fishermen based on the Isle of Mull on Scotland's west coast. The approximate route taken on this particular trip is outlined on the map in Fig. 2. The fishing location favoured by the crew in question is located off the coast of Mull and is marked by an X on the map. However, due to unfavourable weather conditions a longer route up to the Isles of Rum, Eigg and Muck was followed. The return time, not including time spent hauling and deploying creels, was $4 \mathrm{~h}$. According to the fishermen the decision to fish along this route was taken frequently during May 2011, a month that produced uncharacteristically bad weather conditions.

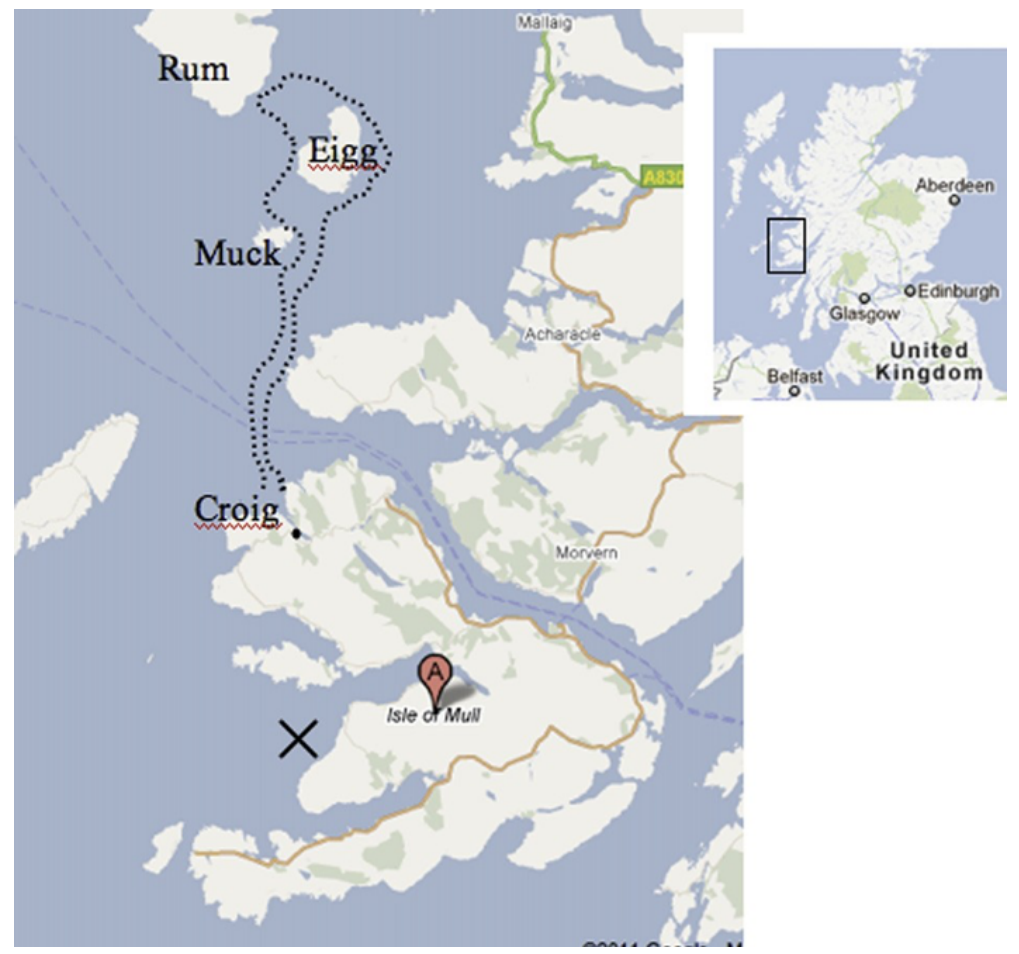

Figure 2. Map showing Isles of Mull, Eigg, Muck and Rum and approximate route taken by the corresponding author with the creel fishermen. Adapted from Google Maps. 
One emerging actant in this case is the weather. The relationship between weather conditions and the fishermen doesn't appear to be accommodated by fishing effort data collated by the Scottish Government. The story told by maps in the Marine Atlas of where vessels spend most of their time fishing (see Fig. 3) does not necessarily reflect the trip described above or the ways in which fishermen react to shifts in the weather. Qualitative research amongst fishing communities can provide a more accurate picture of when and why alternative fishing sites are sought. These accounts can explain temporal changes in behaviour. Were this particular fisherman asked to mark on a map where he deployed his creels, an honest answer would result in an area much larger than is required to provide one catch of crabs and lobsters. The reason for this is that the area would have to cater for unforeseen events as dictated by the weather and ecological changes etc. The time spent in alternative sites during May would not register on annual averages, and yet the fishermen in the area do talk of having to change their locations more frequently. Therefore, fishing effort calculated on engine size and calendar days and displayed on a map might prove misleading in this period of change. Nevertheless, maps and GIS create boundary infrastructures that direct marine governance and are used to inform important decisions.

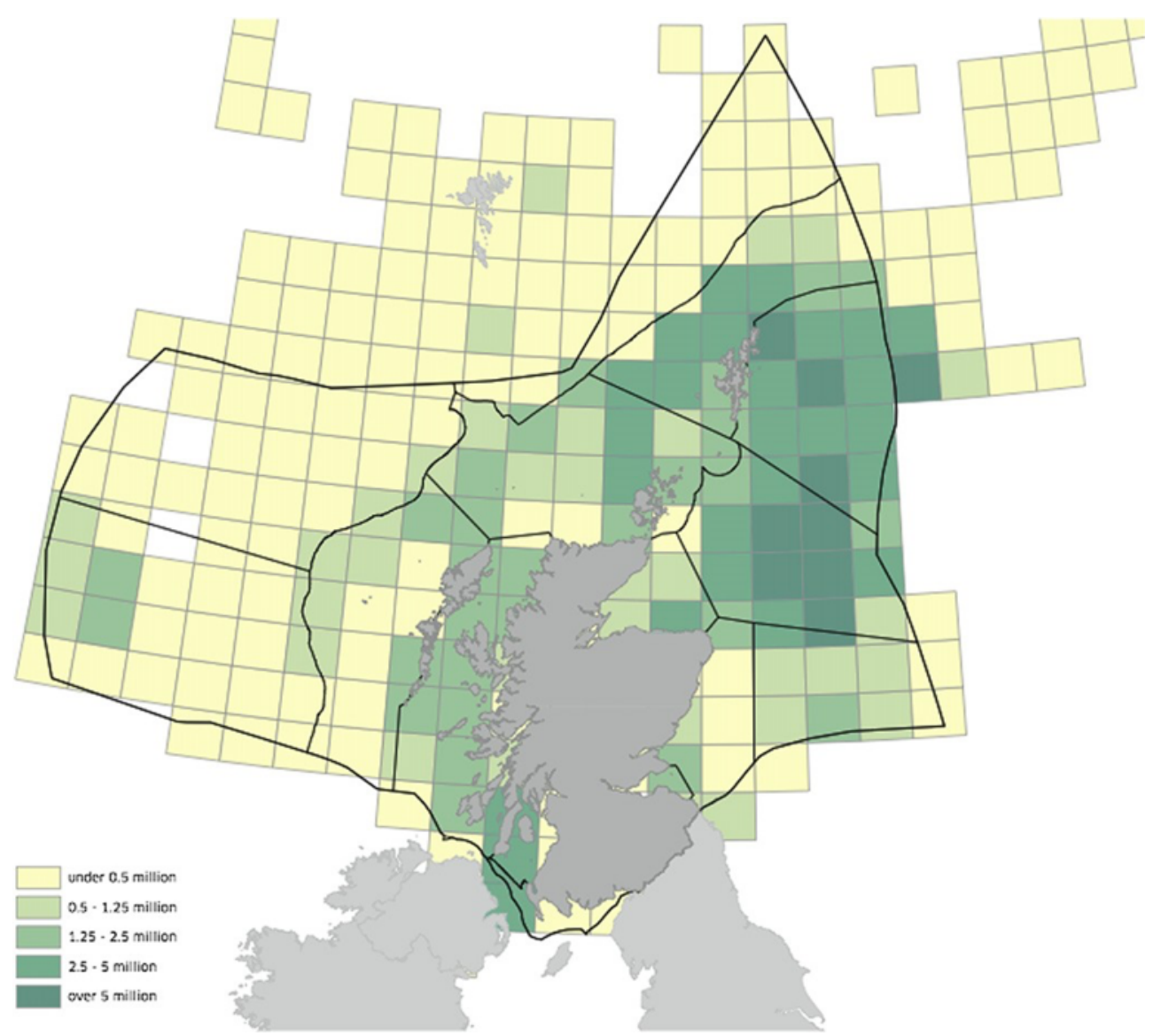

Figure 3. Average effort (kw Days) in Scotland's seas by all UK vessels (all lengths) 2005e2009. Adapted from The Marine Atlas (Baxter et al., 2011, p. 148), Marine Scotland. Note: no kw Days effort data for non-UK vessels. Rectangles where no effort by UK vessels was recorded are not coloured. 
If we extend the network analysis even further then another relationship emerges, namely that between the fisherman and his boat engine. The creel boat referred to above was just shy of 10 $m$ in length and had been in service for less than 2 years. As such, the engine had little wear and was still very efficient. This is not the case for a lot of small fishing boats, which can be in service for decades and inevitably lose engine efficiency, requiring more fuel (i.e. more kWs) to travel the same distances. Although the efficiency does not affect engine size, more time at sea is required to reach the same locations and achieve the same catch rates. In kw Day fishing effort terms, the fisherman is defined by his engine. Both are reliant on one another to fulfil their roles and both are on an equal (neither human nor non-human) footing in an ANT analysis of the network that they share. The fishermen are reliant on complex networks involving the weather, tidal ranges and times, ecological shifts, their boat engines and kw Day statistics, and these networks disappear to be replaced by 'fishing effort' data in the Marine Atlas. Choices on where and when to fish form part of the "human dimensions of the marine environment" (St. Martin and Hall-Arber, 2008 p. 785) that are often overlooked in spatial analyses. Mapping practices often ignore these, and even wider issues from the social landscape, an omission that St. Martin and Hall-Arber (2008) refers to as the "missing layer" in decision making.

The map in Fig. 3 is taken from the Marine Atlas and shows how kw Day data has been represented. The map provides clear indications of where fishing activities are focused around Scotland. In addition to the issues of weather and engine efficiency discussed above, there is another reason to question the zoning pattern here. Maps are typically divided into grids, which is representative of best-fit and categorisation practices. Some important points have to be made about this. Firstly, square grids cannot represent fishing activities or the marine ecosystem. The seas, and the fishing activities carried out at sea, are fluid and not restricted to straight lines and boundaries. The map demonstrates the imposition of boundary infrastructures that simply do not reflect the realities of the marine environment. There is potential to develop alternative and more dynamic maps that might negate some of these restrictions (see Section 9).

\section{Engineering seascapes}

One danger of this misrepresentation is that the use of square units to denote fishing effort will begin to shape the reality of marine management and our impact on the marine environment. As marine use becomes increasingly restricted to specific zones, the seascapes, like Robbins' landscapes (in Zimmerer and Bassett, 2003), will be engineered to suit measurement rather than the other way round. This could lead to major changes in marine conditions as marine space uses change accordingly. By revealing complex and delicate networks it is possible to show how science not only provides knowledge "but also helps to build its governance instruments through the construction of critical limits and measuring devices that become the foundation for restrictive regulations" (Knol, 2011a, p. 38). If these critical limits and measuring devices rely on drawing straight lines on a marine map then they can be potentially damaging to dynamic ecosystems. There is a real possibility that realities can be created by maps, rather than simply represented by them. For example, Robbins (2003) showed how satellite images of terrestrial areas in India only tell a story of previous land use debates rather than inform us 
about land cover. High tech images of seabeds will also tell the story of zoning practices in instances where they are altered or damaged (such as by trawling or renewable technology installations). If fishing regulations and other necessary management initiatives could be designed to better match natural ecosystems then detrimental impacts could be reduced. This is one challenge faced by those seeking to spatially plan maritime activities.

\section{Maps on the front line}

It is not sufficient to point to the flaws in mapping procedures and outcomes. ANT demands that we demonstrate how maps have become the familiar networks, or the agents, texts and devices, described in Law's punctualisation process (Law, 1992). Maps have become an obligatory passing point (OPP) for all involved in the management and use of Scotland's seas. Politicians, scientists and large corporations are able to "impose and stabilise the other actors" that they define, a process that Callon also describes as their being "locked into place" (Callon, 1998, p. 71). Maps allow them to do this. The general view of maps as being ontologically secure facilitates this strategy because we are inclined to trust what they portray. Maps fulfil the role of the Law's agents and texts (1992) in that they are assimilated into the everyday lives of marine users. The potency of maps has been increased by the use of high-tech portable devices on which they can be viewed. Maps can now be easily transferred to almost any location where they can have a huge influence on targeted actors.

In order for maps to have this influence the stakeholders are often put into direct contact with them and this is happening on a more regular basis. Elements of Scotland's Marine Plan are deliberated and communicated in regular fora and workshops, ${ }^{1}$ which involve stakeholders from all sectors. This resembles the way that the research questions about the scallops of St. Brieuc Bay became the point through which all stakeholder engagement had to pass (Callon, 1998). 'Problematization' (Callon, 1998, p. 69) refers to the way in which actors are funnelled into a specific question or purpose. The result is that it becomes impossible to engage in a topic without doing so in the context of this purpose. Maps of Scotland's seas such as those collated in the Marine Atlas are the spatial representations into which actors are drawn. Decisions are made based on maps and then depicted on maps. Having attended stakeholder meetings in Edinburgh, it is clear that the drive for ever better maps of marine spaces is a top priority. Whilst important to our management of natural spaces, there is a danger that this OPP blinds stakeholders, scientists and policy makers to crucial factors that cannot be mapped, such as those explored above. As a social scientist attending these events it also became apparent that they are defined by scientific priorities. The creation of management plans might benefit from a more genuine inclusion of non-scientific actors, experts and stakeholders that reaches beyond the online feedback opportunities available on the Scottish Government website. Greater involvement of social scientists, for example, might yield more balanced results in stakeholder engagement exercises. It is hoped that the insights provided in this paper might help build a case for this. At present the corresponding author feels that public engagement in marine management planning often consists of informing the public of the changes being discussed and, ultimately, made. 
${ }^{1}$ Such as the series of workshops held in 2011-2012 on Marine Protected Areas. Information available at: http://www.scotland.gov.uk/Topics/marine/marine-environment/mpanetwork/engagement.

\section{Redefining actors}

ANT also aims to expose instances of how actants' roles are redefined within the MSP network and are being transformed. To an extent, fishermen have been re-defined as data collectors and have become an extension of scientific practices. Most boats are now fitted with a modern plotting device, which aids them in marking the most productive fishing areas and which "records seabed nature and topography" (Turnbull, 2011). The most popular devices are made by Olex ${ }^{\circledR}$. Every trip fishermen make adds data to this system and then they are called upon to contribute this data to scientists such as those involved in the Marine Atlas. Although the fishermen are not obliged to supply the information from their plotting systems, it does alter their role somewhat in relation to central authorities. Fishermen are aware of the value of the information that they possess. No sustained scientific research effort could match them for hours spent at sea or the volume of data collected.

The skipper aboard the Isle of Mull creel boat commented on how useful the Olex ${ }^{\circledR}$ system is for plotting his favoured fishing grounds but also on the irony of providing information that could lead to fishing restrictions and the establishment of marine protected areas. Although he was in favour of imposing restrictions on creel fishermen, who have not been subjected to the restrictions imposed on other fishing sectors, there was clear hesitation on the topic of volunteering his information for spatial analysis activities. The role of the fisherman has become more politicised as their activities have become more useful to the scientists working with the Scottish Government. Consideration of how fishermen are defined and define themselves is important because MSP can have a real impact on what fishermen and the fishing industry become. Landscapes can be altered by the way they are measured and represented, and stakeholders' roles can also transform if they occupy a central position in collecting the data that allows mapping to continue and to evolve.

The important points from Sections 5, 7 and 8 above are portrayed in the diagram in Fig. 4 . Some of the stakeholders can be seen entering negotiations and workshops aimed at improving marine management. There are no alternative marine management activities and they lead to the obligatory passing point of mapping processes in the context of marine spatial planning. The two outcomes from this process are the emergence of management plans and of maps. These maps go on to inform stakeholders from the beginning of the process and also enter at the negotiating stage. The actants that have emerged through this paper (i.e. the weather, boat engines and tides) are also listed but they are excluded from the negotiating stages where scientists, cartographers, energy industry representatives and political influences dominate proceedings. These actants do, however, impact management plans and the outcome of these plans in ways discussed above.

\section{Concluding remarks}

This paper has considered the mapping central to marine spatial planning under Scotland's National Marine Plan from a fresh perspective and, in doing so, has teased out some important 
considerations. Critical cartography demonstrates some of the complex relations that make up situated realities, which are not well represented by maps. It encourages us not to accept maps as ontologically secure and, subsequently, exposes the potential frailty of policies shaped by the 'evidence' that maps provide. Actor-Network Theory has proven useful for exploring further the networks hinted at by critical cartography and many of these explorations could be extended to exhume further network connections. The refusal of ANT to accept binary opposites is a constructive criticism that encourages more creative studies of human interactions with marine environments, which could offer important insights for the marine spatial planning process. An example of such a dynamic exploration is the 'collaborative GIS research' of Del Casino and Hanna (2006), which expands on the refutation of binaries and explores 'map spaces' i.e. the myriad of performances that maps can represent and be involved in through their creation and our interaction with them (Del Casino and Hanna, 2006). A more recent example-and one more relevant to marine spaces-is an ongoing art-science collaboration, which articulates fishermen's way of knowing the marine environment through the creation of a dynamic and multi-layered digital map. ${ }^{2}$ Other recent work includes creating maps using a real-time interactive touch-table device combined with stakeholder workshops to articulate local knowledge of the marine environment, and to facilitate negotiation within the marine spatial planning process (Alexander et al., 2012).

\section{${ }^{2}$ http://www.smi.ac.uk/ruth-brennan/connecting-coastal-communities-stage-1.}

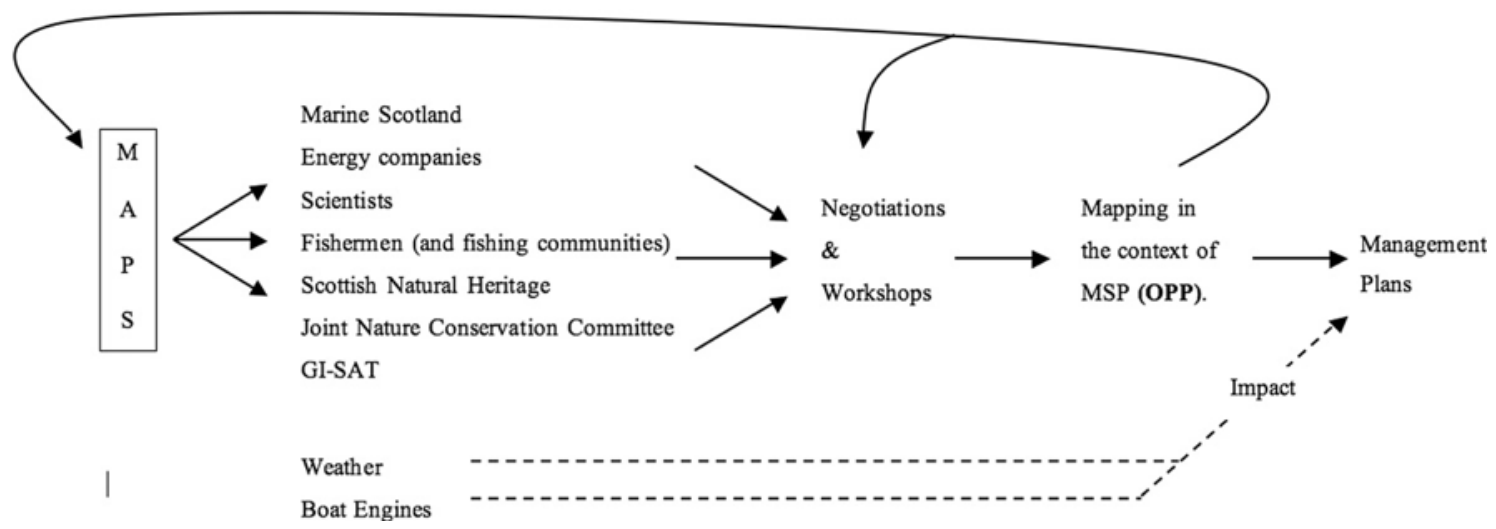

Figure 4. Diagram showing the obligatory passing point (OPP) of mapping and MSP, as well as the exclusion of certain actants, from an Actor-Network Theory (ANT) perspective.

Despite their shortcomings, maps are key to the way marine spaces in Scotland, and around the world, are being managed. They are tactically located in the process of arriving at governance solutions and are very powerful governance tools. This fact makes critical thinking about maps crucial. Considerations should include the potential of a map not only to inform us of the state of a marine space but also the possibility that that space becomes what is depicted, as with the engineering of seascapes discussed above. As such, maps need to be as well informed as possible and stories that marine space users have to tell count towards this information, which is an important step in reducing the dominance of science in map making. These same marine space users, such as the fishermen focused on in this account, can be redefined as new maps 
are created and the policy landscape changes. This can have an enormous impact on society, nature and social nature.

With the policy landscape changing so rapidly in Scotland and with the nation enjoying new autonomy over its marine space, the opportunity for ensuring the sustainability of Scotland's seas is huge. Using scientifically sound methods to inform and implement marine spatial planning is one way to seize this opportunity. However, there is often a perceived disconnect between marine environments - especially those further from the coasts - and society, and a view that scientists know best how to govern these areas. Social science must avoid being muted as Scotland engages in ambitious projects like offshore renewable energy installations. Every time a natural area is mapped, fished in or considered for development it becomes innately social and we would do well to respect that fact.

\section{Acknowledgements}

Many thanks to my supervisor, Andrea Nightingale, at the University of Edinburgh, who provided support and feedback for the MSc thesis on which this article was based. Also, thanks to Ruth Brennan whose originality and professionalism made this article possible.

\section{References}

Alexander, K.A., Janssen, R., Arciniegas, G., O’Higgins, T.G., Eikelboom, T., Wilding, T.A., 2012. Interactive marine spatial planning: siting tidal energy arrays around the Mull of Kintyre. PLoS ONE 7 (1), e30031. http://dx.doi.org/ 10.1371/journal.pone.0030031.

Baxter, J.M., Boyd, I.L., Cox, M., Donald, A.E., Malcolm, S.J., Miles, H., Miller, B., Moffat, C.F. (Eds.), 2011. Scotland's Marine Atlas: Information for the National Marine Plan. Marine Scotland, Edinburgh. Available from:

http://www.scotland.gov.uk/Publications/2011/03/16182005/0 (accessed 07.03.12.).

Callon, M., 1998. Some elements of a sociology of translation: domestication of scallops and the fishermen of St. Brieuc Bay. In: Biagioli, M. (Ed.), The Science Studies Reader. Routledge, pp. 6783.

Castree, N., MacMillan, T., 2001. Dissolving dualisms: actor-networks and the reimagination of nature. In: Castree, N., Braun, B. (Eds.), Social Nature e Theory, Practice and Politics. Blackwell, Oxford.

Crampton, J.W., 2009. Cartography: performative, participatory, political. Progress in Human Geography 33 (6), 840-848.

Defra, 2002. Department for Environment, Food and Rural Affairs. Safeguarding Our Seas - a Strategy for the Conservation and Sustainable Development of Our Marine Environment. 
Del Casino, V.J., Hanna, S.P., 2006. Beyond the 'binaries': a methodological intervention for interrogating maps as representational practices. ACME: An International E-Journal for Critical Geographies 4 (1), 34-56.

Douvere, F., 2008. The importance of marine spatial planning in advancing ecosystem-based sea use management. Marine Policy 32, 762-771.

Eden, S., Tunstall, S.M., Tapsell, S.M., 2000. Translating nature: river restoration as nature culture. Environment and Planning D: Society and Space 18, 257-273.

European Commission, 2007. An Integrated Maritime Policy for the European Union. Available from: http://eurlex.europa.eu/LexUriServ/LexUriServ.do?uri=COM:2007:0575:FIN:EN:PDF (accessed 07.03.12.).

European Commission, 2008. Roadmap for Maritime Spatial Planning: Achieving Common Principles in the EU. Available from: http://eur-

lex.europa.eu/LexUriServ/LexUriServ.do?uri=COM:2008:0791:FIN:EN:PDF (accessed 07.03.12.).

Gilliland, P.M., Laffoley, D., 2008. Key elements and steps in the process of developing ecosystem-based marine spatial planning. Marine Policy 32, 787-796.

Government, H.M., 2009. Our Seas - A Shared Resource. High Level Marine Objectives. In Association with the Northern Ireland Executive, Scottish Government and Welsh Assembly Government. Available from:

http://www.scotland.gov.uk/Topics/marine/seamanagement/marineact/Ourseas (accessed 08.03.12.).

Government, H.M., 2011. UK Marine Policy Statement. In Association with the Northern Ireland Executive, Scottish Government and Welsh Assembly Government, March 2011.

Halpern, B.S., McLeod, K.L., Rosenburg, A.A., Crowder, L.B., 2008. Managing for cumulative impacts in ecosystem-based management through ocean zoning. Ocean and Coastal Management 51, 203-211.

Johnsen, J.-P., Holm, P., Sinclair, P., Bavington, D., 2009. The cyborgization of the fisheries: on attempts to make fisheries management possible. In MAST Maritime Studies 7 (2), 9-34.

Kaljonen, M., 2006. Co-construction of agency and environmental management. The case of agri-environmental policy implementation at Finnish farms. Journal of Rural Studies 22, 205216.

Kitchin, R., Dodge, M., 2007. Rethinking maps. Progress in Human Geography 31 (3), 331-344. 
Knol, M., 2011a. Marine Ecosystem Governance in the Making: Planning for Petroleum Activity in the Barents Sea-Lofoten Area. Unpublished Introduction to Doctoral thesis. Available from: http://munin.uit.no/handle/10037/3111 (accessed 07.03.12.).

Knol, M., 2011b. Mapping Ocean governance: from ecological values to policy instrumentation. Journal of Environmental Planning and Management 54 (7), 979-995. Latour, B., 1993. We Have Never Been Modern. Harvard University Press, Cambridge, Mass.

Law, J., 1992. Notes on the theory of the actor-network: ordering, strategy, and heterogeneity. Systems Practice 5 (4), 379-393.

McLean, C., Hassard, J., 2004. Symmetrical absence/symmetrical absurdity: critical notes on the production of actor-network accounts. Journal of Management Studies 41 (3), 493-519.

Murdoch, J., 1997. Inhuman/nonhuman/human: actor-network theory and the prospects for a nondualistic and symmetrical perspective on nature and society. Environment and Planning D: Society and Space 15, 731-756.

Murdoch, J., 1998. The spaces of actor-network theory. Geofimm 29 (4), 357-374.

Nightingale, A.J., 2006. Can Social Theory Adequately Address Nature-society Issues? Do Political Ecology and Science Studies in Geography Incorporate Ecological Change? Online Papers Archived by the Institute of Geography. School of Geosciences, University of Edinburgh. Available from: http://www.era.lib.ed.ac.uk/handle/1842/1437 (accessed 07.03.12.).

Reed, S.E., Boggs, J.L., Mann, J.P., 2012. A GIS tool for modeling anthropogenic noise propagation in natural ecosystems. Environmental Modelling \& Software 37, 1-5.

Robbins, P., 2003. Fixed categories in a portable landscape e the causes and consequences of land cover categorization. In: Zimmerer, K.S., Bassett, T.J. (Eds.), Political Ecology - An Integrative Approach to Geography and Environment-Development Studies. The Guilford Press, New York, pp. 181-200.

Roger, K., Moore, S.A., Newsome, D., 2009. Wildlife tourism, science and actor network theory. Annals of Tourism Research 36 (4), 645-666.

Scottish Government, 2007. Recommendations of the Advisory Group on Marine and Coastal Strategy: a Follow up to Seas the Opportunity: a Strategy for the Long Term Sustainability of Scotland's Coasts and Seas (2007). 8. Summary of Recommendations. Available from: http://www.scotland.gov.uk/Publications/2007/03/08103826/8 (accessed 07.03.12.).

Scottish Government, 2011a. Scotland's National Marine Plan e Pre-consultation Draft. Available from: http://www.scotland.gov.uk/Publications/2011/03/ 21114728/0 (accessed 08.03.12.). 
Scottish Government, 2011b. Analysis of Written Responses to a Consultation Paper on Proposals for the Creation of Scottish Marine Regions. Available from:

http://scotland.gov.uk/Publications/2011/10/24105640/0 (accessed 07.03.12.).

Smith, G., 2011. Maps, Networks and a Sea that Won't Conform: Thinking Critically about Marine Spatial Planning in Scotland. Master of Science dissertation at the University of Edinburgh. Abstract available at: http://www.era.lib.ed.ac.uk/handle/1842/5210 (accessed 02.08.12.). Whole Document Available on Request from the Corresponding Author.

St. Martin, K., Hall-Arber, K., 2008. The missing layer: geo-technologies, communities, and implications for marine spatial planning. Marine Policy 32, 779-786.

Steins, N.,A., 2001. New directions in natural resource management e the offer of actornetwork theory. IDS Bulletin 32 (4), 18-25.

Turnbull, N., Isle of Mull Fisherman. Personal Communication, Isle of Mull, 14 June 2011.

Vine, M.F., Degnan, D., Hanchette, C., 1997. Geographic information systems: their use in environmental epidemiologic research. Environmental Health Perspectives 105 (6), 598-605. 